\title{
An Analysis of Digital Transformation in the History and Future of Modern Ports
}

\author{
Leonard Heilig \\ Institute of Information Systems, \\ University of Hamburg \\ leonard.heilig@uni-hamburg.de
}

\author{
Silvia Schwarze \\ Institute of Information Systems, \\ University of Hamburg \\ silvia.schwarze@uni-hamburg.de
}

\author{
Stefan Voß \\ Institute of Information Systems, \\ University of Hamburg \\ stefan.voss@uni-hamburg.de
}

\begin{abstract}
Digital transformation is of utmost importance in the business world with major impacts on any of its sectors. Here we consider ports and logistics within maritime shipping to exemplify those developments. That is, as actors in world-wide supply chains, seaports are particularly affected by technological change. Due to the high requirements in the logistics sector, e.g., regarding costs, efficiency, security, and sustainability, digital innovation is essential to stay competitive. Past developments show how digital innovation can shape the modernization of ports. In order to understand future challenges in this area, it is inevitable to review the outcomes of past developments and their impact on port operations. In this paper, we provide an extensive analysis of digital transformations in seaports. We identify three generations and analyze the stages of respective digital transformations using a well-known model from literature. Based on the observations, we identify important aspects and challenges.
\end{abstract}

\section{Introduction}

Modern seaports play an important role in guaranteeing efficient and safe cargo flows in global logistics networks. Moreover, ports offer various kinds of value-added logistics (VAL) services, for example, to facilitate postponement strategies of global supply chains. The efficiency and safety of related cargo flows is highly dependent on associated information flows. Since the beginning of containerization in the 1960s, the adoption of information technology (IT) and information systems (IS) has evolved to an indispensable success factor for the competitiveness of ports, facilitating communication and decision making for enhancing the visibility, productivity, efficiency, and safety in port procedures that are impacted by various conditions. Moreover, a better integration of governmental bodies to standardize and harmonize reporting formalities becomes increasingly important.

Under the notions "digital transformation," "ITenabled business transformation," or "information system-enabled organizational transformation," literature provides models to identify key aspects of such transformations and gives support in shaping business changes. A classification of IT-enabled business transformation into five levels, ordered by their degree of impact, is provided by the, in literature wellrecognized, model of IT-enabled business transformation proposed by Venkatraman [1].

We aim to put this into perspective with respect to the development of ports. First of all, we categorize major developments into three main generations of digital transformations. For each generation, we retrospectively review main drivers and developments that either required or enabled digital transformation. Then, we analyze past digital transformations by applying the five levels of Venkatraman's model. Although the model is restricted to a single business perspective, this paper applies the model for further analyzing the dependencies between digital transformations on a global and local, actor-related port level. In this regard, we discuss current and future trends as well as challenges for both industry and research. To the best of our knowledge, the paper is the first one to explore the implications of digital transformation in ports and complements a recent review on applied IT/IS solutions and related works [2]. In a nutshell, the contribution of our paper is threefold:

1) We provide an extensive overview on the development of seaports with a particular regard to digital transformation.

2) The levels and interrelationships from a port's and actor's perspective are deeply analyzed.

3) We identify and explain important implications, in particular with respect to smart ports.

The remainder of this paper is structured as follows. In Section 2, an introduction to digital transformation and an overview on the applied model is provided. Section 3 gives an overview on the three identified generations of digital transformation including a brief background about the interplay between port development and IT development and an extensive analysis of corresponding digital transformations. In Section 4, we discuss implications and challenges of current developments for near future digital 
transformations in smart ports. The different sections are moderately interleaved with related literature references for further exploration. Finally, conclusions are outlined in Section 5.

\section{Digital Transformation}

Different terms are used to refer to transformations in organizations that are driven by new enabling IT/IS solutions and trends. For ease of exposition we use the term digital transformation to exclusively refer to these transformations. Currently, enablers of digital transformations include novel delivery models (e.g., cloud computing), pervasive computing (e.g., internet of things, cyber-physical systems), mobile computing, social media, as well as new tools and methods to exploit data (e.g., business analytics, machine learning). Allowing the sensing, collection, management, allocation, distribution, and use of information, IT/IS is an enabler for business transformation with consequences on tasks, information flows, knowledge, culture, and people [1]. Davenport [3] emphasizes the role of IT for redesigning business processes by enabling organizational streamlining, capturing and distributing information, coordination, monitoring, analysis and decision making, and parallelizing of tasks (see also [4]). The model of Venkatraman [1] further distinguishes between different levels of digital transformation that go beyond the traditional business process reengineering perspective. In recent decades, this model has attracted a lot of attention in academia. Both definitions have in common the mutual and bidirectional relationship between IT and the organization [4]. More precisely, Venkatraman et al. [5] explain the interrelationships between four key perspectives for strategic business-IT alignment. As the model allows us to categorize and analyze digital transformations in more detail, we apply this model for analyzing past and current developments in ports.

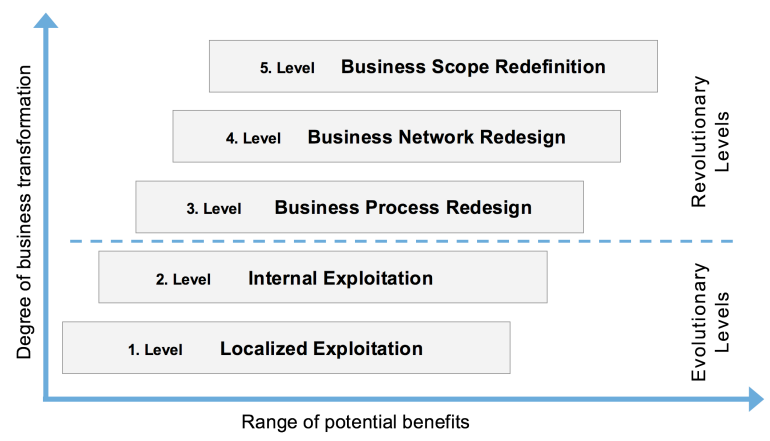

Figure 1. Model of IT-enabled business transformation by Venkatraman [1]
In general, the model distinguishes between five different levels of digital transformation. As outlined in Figure 1, the levels are arranged according to their impact on the organization ranging from a slight transformation of certain business activities to a redefinition of business models and scope (see explanations in Table 1).

Table 1. Levels of IT-enabled business transformation by Venkatraman [1]

\begin{tabular}{|c|c|}
\hline Level & Description and Implications \\
\hline $\begin{array}{l}\text { 1. Localized } \\
\text { Exploitation }\end{array}$ & $\begin{array}{l}\text { - Deployment of standard IT functionality for } \\
\text { supporting individual business activities. } \\
\text { - Implies little changes of business activities; } \\
\text { low impact on related business processes. } \\
\text { - Full potential of deployed IT is not exploited; } \\
\text { no long-term competitive advantages. } \\
\text { - Examples besides basic IT functionality (e.g., } \\
\text { booking, accounting) are production planning } \\
\text { and data warehouse management solutions. }\end{array}$ \\
\hline $\begin{array}{l}\text { 2. Internal } \\
\text { Integration }\end{array}$ & $\begin{array}{l}\text { - Technical and organizational integration. } \\
\text { - Trans-functional process integration builds } \\
\text { the basis for business-IT alignment [6]. } \\
\text { - Examples are enterprise resource planning } \\
\text { (ERP) systems and data warehouses (DW). }\end{array}$ \\
\hline $\begin{array}{l}\text { 3. Business } \\
\text { Process Re- } \\
\text { design }\end{array}$ & $\begin{array}{l}\text { - A redesign of organizational structures and } \\
\text { business processes is necessary to fully } \\
\text { exploit new IT/IS capabilities [3]. } \\
\text { - The adoption of a DW, for example, may not } \\
\text { only change decision making, but also allow } \\
\text { to identify new potentials for improvement. } \\
\text { - On the other hand, a redesign of business } \\
\text { processes may lead to new DW requirements. }\end{array}$ \\
\hline $\begin{array}{l}\text { 4. Business } \\
\text { Network } \\
\text { Redesign }\end{array}$ & $\begin{array}{l}\text { - Focus on the redesign of business networks } \\
\text { from an inter-organizational perspective. } \\
\text { - Technical enablers can be common data } \\
\text { exchange standards and platforms. } \\
\text { - Involves strategic considerations on potential } \\
\text { collaborations to benefit from, e.g., shared } \\
\text { knowledge and collaborative planning. }\end{array}$ \\
\hline $\begin{array}{l}\text { 5. Business } \\
\text { Scope Re- } \\
\text { definition }\end{array}$ & $\begin{array}{l}\text { - Includes the modification, elimination, } \\
\text { outsourcing, and expansion of former } \\
\text { business models and processes given new } \\
\text { IT/IS capabilities and transformed processes. } \\
\text { - May involve the creation of new strategies, } \\
\text { products/services, and partnerships. }\end{array}$ \\
\hline
\end{tabular}

\section{Generations of Digital Transformations}

We differentiate between three main generations in the development of digital transformation in seaports: paperless procedures, automated procedures, and smart procedures. Thus, the focus of these generations is on the impact of the most important IT/IS enablers on the operations of both ports in general and port actors. In the following subsections, we first explain major events in 
port development and then analyze the associated levels of transformation. A tabular summary with main findings and the scope of digital transformations according to Venkatraman's five model levels is provided for each subsection. For a background on the port business and related economics considerations see, e.g., contributions in Talley [7].

Regarding container terminals as major drivers within the port business, we refer to the survey of Stahlbock and Voß [8].

\subsection{First generation (1980s): Transformation to Paperless Procedures}

Beginning in the $1960 \mathrm{~s}$, containerization and intermodal transportation profoundly changed existing transportation systems to integrated transportation systems. Due to the crucial role of ports as intermodal logistics hubs, it was not sufficient to focus only on cargo flows, but to ensure efficient information flows. The development of electronic data interchange (EDI) systems in the 1960s and 1970s paved the way for the first digital transformation in the maritime shipping industry. However, a long standardization process had to take place before port communities could fully utilize new opportunities of EDI. The development of the first EDI-based port community system (PCS), enabling an electronic document exchange between actors involved in port operations, started in 1983 with DAKOSY ${ }^{1}$. The development of maritime industry-specific UN/EDIFACT message standards in the late 1980s further fostered this development. In the late 1980s, important paper documents, such as the bill of lading (BoL), were transformed into electronic documents (see, e.g., the SeaDocs project starting in 1986; CMI Rules for Electronic BoL in 1990). In the late 1980s, the first commercial terminal operating systems (TOS) were developed and henceforth built the foundation for datadriven planning and automation in container terminals. At that time, customers increasingly demanded VAL services, requiring an efficient coordination of activities between actors [9].

By analyzing the first periods of dramatic changes in ports, we observe that digital transformation had to take place on several levels. In the context of logistics chains and ports, however, we also see that the business processes are naturally dependent on efficient information flows in the overall business network. Large port actors, in particular terminal operators, firstly deployed mostly isolated IT systems and applications to provide at least basic IT functionality. The integration of different internal systems and applications was essential to support individual terminal

\footnotetext{
${ }^{1}$ https://www.dakosy.de/en/solutions/
}

operations like berth and yard activities. Major advances in ERP systems during the 1980s, driven by companies like SAP, gave rise to the idea of developing TOSs integrating data from different business activities taking place within terminals. Having an integrated view on business processes, overall processes needed to be adopted accordingly to improve the overall planning, management, and coordination of activities. This ITenabled functional integration allowed more efficient container handling and thus was essential to achieve a competitive edge. The development of off-the-shelf TOSs in the late 1980s may have reduced competitive advantages of individual terminal operators, but led to major advancements in operating container terminals.

Knowing that efficient port procedures are highly dependent on the efficiency of all involved organizations and the handover of containers in-between, the need for inter-organizational systems quickly became apparent. As indicated, the development of such systems was highly reliant on common technical standards. The adoption of EDI based on UN/EDIFACT had a strong impact on the overall efficiency of logistics chains by speeding up communications, improving collaboration, decreasing the volume of paper, and reducing costs [10]. The development of EDI systems in the form of PCSs, starting in the early 1980s, focused on the needs of major port communities. The availability and quality of PCSs is still seen as an essential factor for growth and competitiveness of ports [11]. The introduction of EDI systems required community actors to make huge investments in appropriate IT infrastructure and setups, to share information, and to change business processes accordingly. Thus, the development of business networks required actors to firstly transform internal IT in order to comply to those standards. Consequently, actors could again achieve competitive advantages on the local port level by an early adoption of the required IT functionality (level one) and integration of required data from internal systems (level two). Port community actors, who were capable of fulfilling all requirements and adequately adjusting their processes, were then able to additionally benefit from the competitive advantages on a global scale. However, the success of the digital transformation was highly dependent on the port community's willingness to participate.

Generally, we can summarize (see Table 2) that one of the major changes in the first generation was the reduction of paper-based processing in interorganizational business processes. However, port operations are often, even today, still highly reliant on the printed version of those documents for handling terminal and administrative procedures (e.g., for the pickup/delivery of containers by drayage firms). This often leads to process errors and inefficiencies, e.g., due to false, outdated, or incomplete information. The major 
Table 2. Summary of the First Generation of Digital Transformation (1980s)

\begin{tabular}{|l|l|}
\hline Events & $\begin{array}{l}\text { Containerization led to high requirements on efficient cargo and information flows to succeed in the new role of ports as } \\
\text { integrated transportation systems and logistics hubs, which had to be supported by huge investments into infrastructure, } \\
\text { superstructure, and equipment. }\end{array}$ \\
\hline ST/IS & e.g., EDI, PCS, UN/EDIFACT standards, TOS. \\
\hline - Level 1: Support of individual activities by implementing basic, usually off-the-shelf, and isolated IT functionality \\
(e.g., booking, invoicing, accounting); creation of basic conditions for supporting inter-organizational information \\
exchange using EDI standards. \\
$\begin{array}{l}\text { - Level 2: Integrated view on core business processes within terminals by developing TOS; integration of data sources } \\
\text { necessary for supporting collaboration with external actors. }\end{array}$ \\
$\begin{array}{l}\text { - Level 3: Integration enables planning, management, and coordination of interdependent activities within the terminal. } \\
\text { - Level 4: Paperless interactions between interacting actors in inter-organizational business processes. }\end{array}$ \\
$\begin{array}{l}\text { - Digitalization established the foundation for efficient terminal operations and automation as well as to expand the } \\
\text { traditional business, such as by introducing new VAL. } \\
\text { - Inter-organizational platforms in form of PCSs reduced paper-based processing, but are highly dependent on the port } \\
\text { community's willingness to adequately participate; however, in their current form, they are limited to a passive } \\
\text { exchange of static documents rather than supporting active interactions among actors. }\end{array}$
\end{tabular}

advancement thus was the availability and management of information to better plan and complete internal processes before and after their execution, respectively. Thus, we see that the execution of business processes within integrated transportation systems are performed completely autonomously meaning that all involved actors are self-responsible in performing their tasks. However, a lack of actual (external) information during process execution could be another source of inefficiencies. This may also include information on the current situation in ports and the current status of cargo, important for making decisions on when and how to perform subsequent tasks as well as to prevent and react to process errors, which might also occur in preceding business processes performed by other actors. A lack of overall control and visibility may result in cascading errors and delays in related supply chain processes.

We further observe that the need and degree of digital transformation was highly dependent on the transformation of the port itself. Major ports, consisting of a large port community connecting terminals, authorities, haulage companies, and other stakeholders providing transportation, logistics, and administrative services, urgently required means to better communicate and collaborate. At the same time, those ports could build on existing competitive advantages and had the strength to invest in appropriate IT/IS solutions. In case we regard the overall port as a business, however, the development of a PCS can be seen as just providing basic IT functionality supporting the asynchronous communication in cargo export and import processes (level one) as well as the collection of those documents using a common document platform (level two). This standard IT functionality can be imitated by strong competitors, which is likely the reason for the rapid development of several PCS solutions in major ports during the 1980s and 1990s.

\subsection{Second Generation (1990s - 2000s): Transformation to Automated Procedures}

In the 1990s and 2000s, established and new IT/IS solutions provided an essential foundation to greatly automate container handling procedures, in particular in container terminals. In the early 1990s, laser technologies found their way into terminal operations containing functions such as profiling, locating, distance detection, collision prevention, and damage detection. Providing these functions, laser technologies are regarded as key technology for facilitating automated and safer handling solutions in automated container terminals [12]. This major step towards automated container terminals required a seamless integration between the automated handling equipment and the TOS containing required information including work orders. The trend of using IT/IS as a backbone to further automate procedures and increase the visibility of port operations continued during the mid and late 1990s. In particular automatic identification and positioning technologies were introduced in the mid 1990s to improve the efficiency and safety of port operations. Other information systems, such as vessel traffic services (VTS), benefited from the application of automatic identification systems (AIS) in the late 1990s, allowing the tracking of vessels as a means to prevent collisions.

To better utilize the capacity of largely increasing vessel sizes while maintaining service quality in liner shipping, the first strategic global liner shipping alliances were formed in the mid 1990s. This required a harmonization of services as well as the IT/IS integration among participating actors. At the same time, the continuous growth in container shipping for the first time seemed to reach the limits of some major ports' infrastructures leading to severe traffic and environmental problems. 
One of the factors was the ever-increasing vessel size leading to peak loads regarding the hinterland transport. Initiatives were formed to propose approaches for addressing those future challenges and imposed state regulations (see, e.g., TEA-21 in 1998, CEPA in 1999). First approaches to address the severe traffic problems were introduced in the beginning of the 21 st century. At the Los Angeles/Long Beach ports, the development of the first truck appointment system (TAS) started in 2002 in response to state legislation aiming to reduce truck queuing at terminal gates in order to mitigate vehicle emissions. Again, new information systems were needed to allow the transformation of drayage operations. Terminal operators furthermore asked drayage firms to equip their trucks with RFID (radio-frequency identification) tags in order to allow, for instance, prior identification checks.

We further observe that there was a growing interest in e-commerce systems in the late 1990s, for example, to facilitate trade and shipping management between carriers, shippers, and forwarders. This can be explained by the general euphoric attitude towards ecommerce, today known as dot-com boom, which resulted in new e-commerce platforms. INTTRA, developed in 2000, for example, is still the leading emarketplace for the maritime industry supporting maritime shipping commerce. Moreover, to streamline the national and cross-national exchange of information with governments, increased demand for single-window systems began to rise in the mid 2000s.

The global economic crisis of 2008-2009 led to a more stringent evaluation and selection of ports intensifying the competition among ports drastically. A structural implication was that sustainable performance can be achieved through two key strategies [13]. While the first strategy aims to strengthen the cooperation between ports, the second strategy focuses on improving the coordination between port community actors, e.g., to solve hinterland accessibility problems. The roles of port authorities and terminal operators in restructuring and enabling an active coordination of actors have become increasingly important. Nowadays it is further crucial to be more responsive to changing circumstances, such as regarding customer needs and process errors. In this context, visibility and decision support based on accurate data are essential. Instead of focusing on exchanging static electronic documents for managing the transport and handover of containers, a new era of contextual real-time data processing for enabling smart procedures was about to begin.

In terms of digital transformation (see Table 3), the focus of the second generation was clearly on the integration of terminal equipment and the terminals' IT/IS infrastructure to support automation in terminals.
In the first stage, terminal operators adopted new handling technologies equipped with sensors and laser technologies allowing an autonomous handling of cargo. However, the productivity of automated terminals was highly dependent on the design and development of control software [14]. The final step was to integrate the control software with the terminal's TOS. Thus, we observe that the previous generation built a necessary basis, and competitive edge, to support the extension of terminal capabilities with automated terminal equipment. To successfully utilize those new technologies, automation implied fundamental changes in affected processes. A major change was the collection and allocation of internal information, requiring an alignment of IT/IS with those processes and information management. Moreover, additional checks and control mechanisms needed to be implemented to ensure the performance and safety in those semi-automated processes, in particular when humans are involved. While automation led to labor reductions, a high level of expertise was required for controlling activities. We generally observe that this generation led to an almost complete dependence on IT/IS in container terminals.

Besides developments in forming global emarketplaces as a means to establish trade networks, a major concern has been the growing traffic and environmental issues. Driven by resulting transportation problems and new government regulations, major ports needed to find integrated solutions for the whole port environment. IT-driven initiatives indicated that a transformation is only possible if a critical mass of actors adapts their behavior, i.e., processes, requiring the willingness to participate and to share information. In the case of the Los Angeles/Long Beach ports, a fine was introduced to influence the - beforehand autonomous decisions of drayage firms on drayage planning. A TAS was used to integrate port actors and manage terminal appointments. From a port perspective, the resulting network allowed to better control and coordinate port activities (level four) in order to lower the effect of peak traffic periods. Similar to the adoption of PCS, terminal operators and drayage firms had to integrate the TAS with internal IT systems in order to manage their appointments (level two). Moreover, some ports force drayage firms to equip vehicles with identification technologies (level one). A business process redesign was only necessary at container terminals, for instance, to adapt gate procedures. Redesigning container drayage procedures was not necessary as only the time of activities was affected.

Similar to PCS, we observe that the mostly static information constrains the flexibility of port and terminal operations. In a dynamic transportation system, container vessels might be delayed or drayage trucks might be over-punctual, and vice versa; with a lack of 
Table 3. Summary of the Second Generation of Digital Transformation (1990s - 2000s)

\begin{tabular}{|l|l|}
\hline Events & - Digitalization enabled a high degree of automation in terminal operations (e.g., ECT Delta Terminal in Maasvlakte \\
& Rotterdam, Netherlands, in 1993; CTA Container Terminal Altenwerder in the Port of Hamburg, Germany, in 2002). \\
& - First global strategic liner shipping alliances are formed in the mid 1990s. \\
& - For the first time the continuous growth in container shipping seemed to reach the limits of some major ports leading \\
to severe traffic problems and environmental impacts in the mid 1990s. & - Growing interest in e-commerce systems in the late 1990s. \\
& - Increasing demand for single-window systems in the mid 2000s. \\
\hline IT/IS & Global economic crisis of 2008-2009 led to a more stringent evaluation and selection of ports.
\end{tabular}

actual real-time data integration, however, business processes cannot respond to the current situation and changing circumstances. Another interesting aspect is the used approach to establish the willingness to participate. While some ports exclusively focus on explaining the resulting benefits of a new system for the respective port actors (e.g., reduced waiting times at terminal gates for drayage firms), others make the system mandatory and may also introduce punitive measures, such as fines. In the Port of Hamburg, for example, it was recently decided to make the preregistration and appointment booking mandatory after operating the TAS for several years. The reason may be the new developments towards a smart port aiming to improve traffic flows and coordination in ports.

\subsection{Third Generation (2010s - today): Transformation to Smart Procedures}

While the majority of the stakeholders in the maritime industry is still discussing terms like internet of things, big data, analytics, mobile computing, and cloud computing, we see the first implementations of those concepts in ports. In the Port of Hamburg, for instance, the Hamburg Port Authority (HPA) started the project smartPORT logistics ${ }^{2}$ (SPL) in 2010 with the objective to improve traffic and cargo flows within the port area by investing in modern information systems and port infrastructure. The main idea is to integrate

\footnotetext{
${ }^{2}$ http://www.hamburg-port-authority.de/de/smartport/logistics
}

different traffic control centers (road, sea, railway) into a main port traffic center that allows decision-making and an on-going interaction with actors being actively involved in transport activities based on real-time data. This includes an integration of traffic and infrastructure management thus allowing to route traffic flows dependent on the current traffic situation in the port. A variety of sensors and actuators has been attached to the port infrastructure to facilitate a better adaptability and an eco-friendly use of infrastructure, for instance, by coordinating river and road traffic flows through moving bridges or by controlling the road lighting, respectively. Moreover, sensors are used to measure the conditions of infrastructure and environmental impacts. The collected data is processed in isolated systems and then transferred to a central information system to explore, aggregate, and distribute information over different channels to various involved actors and decision makers. A central cloud-based information system shall facilitate the integration and provides the necessary resources to flexibly fulfill the computational requirements of those applications. The port further aims to improve the accessibility by deploying wireless network hot spots. Another major step towards an intelligent control of road traffic is the intended use of mobile technologies. The primary intention is to actively route drayage truck drivers through the port by providing driver assistance based on the individual position of trucks in the port. This includes real-time information on the traffic situation and the situation at terminals and depots, estimated time of arrival, and forecasts on free parking 
space as well as individual recommendations prior to and during process execution. A mobile application and a web application have been developed for establishing the communication link to truck drivers and dispatchers, respectively. In a recent work of Heilig et al. [15], a solution based on a mobile cloud platform, utilizing real-time traffic and positioning information of drayage trucks, has been proposed for improving the collaboration and coordination of inter-terminal transports, extending current approaches with route optimization functionality. Also the Port of Algeciras Bay in Spain is driving a digitalization program Algeciras BrainPort 2020 (ABP 2020) ${ }^{3}$ towards datadriven solutions for re-engineering of processes and management tools. These examples show that the maritime industry is undergoing significant changes towards just-in-time logistics, value-added information services, and port-centric decision support. Also other port authorities and terminal operators developed apps to enhance information flows. Moreover, crowdsourcing events were organized in the form of hackathons encouraging students and scholars to create innovative solutions leveraging promising trends. ${ }^{4}$

Besides, initiatives between ports and universities were established to support collaboration and to provide educational programs focusing on interdisciplinary education for future decision makers. In Rotterdam, for instance, the Erasmus Smart Port initiative was formed in 2010 with the aim of comprising all different organizations and smart port activities within the Erasmus University Rotterdam and to establish a close collaboration with representatives from the port community in order to bundle maritime expertise and develop multidisciplinary approaches. ${ }^{5}$

In general, we observe that the initiatives and projects do not only emphasize the need for a more efficient information exchange, but also the importance of decision analytics. Still, a future challenge is the analysis of data in order to make more efficient decisions and to further automate intra/inter terminal and port procedures that can be characterized by their capability to quickly respond to changes and errors (or operational disturbances). The implementation of this vision requires multidisciplinary knowledge and is highly dependent on a successful collaboration between the maritime industry, the IT sector, and research facilities. At the same time, we see that the success of those initiatives is again highly dependent on the willingness of actors to participate. While traditional

\footnotetext{
${ }^{3}$ See, e.g., information provided in https://collaboration.navis.com/ blogDetails?id=906160000000RvIAAU

${ }^{4}$ See the latest edition of such an event at https://www.hafenhamburg.de/en/1-maritime-hackathon-hamburg

${ }^{5} \mathrm{http}$ ///www.rsm.nl/about-rsm/news/detail/1327-creation-of-erasmussmart-port-rotterdam
}

information exchange allowed actors to perform activities and decisions almost autonomously, new approaches require an active and on-going collaboration between the port and involved actors to partly contribute to the common good. Although this causes not only enthusiasm, ports need to continue working on solutions for solving major issues.

While the first and second digital transformation generations mostly focused on establishing the foundation for improved information flows in terminals and port communities enabling and improving terminal automation, trading, and interaction in a local or global context, the on-going third generation mainly focuses on actively measuring, controlling, and assisting port operations and port infrastructure by an improved exploitation of available data sources and continuous interactions in the port community (Table 4). From this, we can conclude that with the third generation of digital transformation ports aim to actively have an impact on the behavior and decisions of actors in order to increase the efficiency in overall port operations and to address certain issues, such as traffic and environmental problems. The current innovative development and adoption of modern IT technologies and systems further indicate that ports increasingly extend their traditional business scope by acting as a port information integrator and provider, which can be categorized as a business scope redefinition (level five). Note that the development and implementation of IT solutions is often outsourced to consultancy firms and IT companies.

In recent years, the primary focus of many major ports was on the development of mobile apps to allow a dissemination of relevant information to port actors for performing and assisting job orders, for instance, information on booked appointments, available parking slots in the port, and container locations, and information about the current status to support drayage truck drivers. The latter could inform about the release status of containers. For improving the data quality, apps further allow to inform port actors about incorrect or incomplete data entries, for example, during the preregistration of truck operations, in order to accelerate gate and terminal procedures. We observe that the adoption of apps might trigger a slight redesign of internal business processes of involved actors (level three) as more accurate status information can be used to optimize activities. However, it requires port actors to adopt the necessary hardware and apps (level one) and to integrate them with their internal systems (level two). Although the adoption barrier and costs are low compared to the introduction of EDI systems of the first generation, it is important that actors understand and highly valuate the benefits of the solution and are able to use it productively. To lower the adoption barrier, major ports have already started several initiatives, for 
Table 4. Summary of the Third Generation of Digital Transformation (2010s - today)

\begin{tabular}{|l|l|}
\hline Events & $\begin{array}{l}\text { - Current trends and emerging technologies in the IT sector foster an improved gathering, storing, processing, and } \\
\text { analysis of various and large data sources. }\end{array}$ \\
& $\begin{array}{l}\text { - Port-centric decision support has become essential to address inefficiencies and bottlenecks on the overall port level. } \\
\text { - Customers increasingly demand value-added information services to get a better insight into related processes. } \\
\text { - Information flows between different ports become increasingly important for establishing successful partnerships. }\end{array}$ \\
\hline IT/IS & e.g., Mobile Technologies, Sensors/Actuators, Cloud Computing, Distributed Computing/Processing, Machine Learning. \\
\hline Scope & $\begin{array}{l}\text { - Level 1: Equipping physical infrastructure and actors with sensors, actuators, and apps. } \\
\text { - Level 2: Integration of real-time data sources, actuators, and external information services. }\end{array}$ \\
& $\begin{array}{l}\text { - Level 3: Improved exploitation of available (real-time) data sources to improve responsiveness and decision making } \\
\text { - Luring process execution require more granular process definitions. }\end{array}$ \\
\hline Impact & $\begin{array}{l}\text { - Sevel 5: Ports increasingly extend their traditional scope by acting as a port information integrator and provider. } \\
\text { (e.g., port authority, third-party provider) requesting actors to partly give away control and follow instructions. } \\
\text { - May facilitate just-in-time and agile logistics by a better coordination and responsiveness to changes/errors based on } \\
\text { different sources of actual data and data-driven decision support solutions. }\end{array}$ \\
\hline
\end{tabular}

instance, to provide free broadband internet access within the port and to organize workshops to explain and discuss the idea of developing mobile solutions. We observe that the sharing of IT infrastructure within the port community, for example based on a cloud platform, builds a common basis for digital transformations in the revolutionary levels.

Basic collection and dissemination of information, however, cannot be referred to as smart. Smart port procedures are business processes that are able to make better use of available resources by improving the coordination of actors and responsiveness to changing circumstances as well as by considering economic and ecologic impacts of actions through the use of various integrated sources of information used to support (near) real-time decision making.

In this regard, current projects (e.g., SPL) further stress the importance of an integration of available data sources. The port introduces new sensor and actuator technologies to actively measure and control port infrastructure, implements new information platforms, integrates legacy systems, and develops apps to exchange information (level one and two). With the integration of different control systems supporting seaside, terminal, and landside operations, it is possible to better coordinate naturally separated transportation systems. This marks a milestone towards just-in-time and agile logistics operations in ports.

To achieve the objectives of this transformation, the port is more than ever dependent on network effects. Thus, port communities need to understand strategic and competitive advantages of participating in this network (level four) and how they are able to adopt new technologies and redesign their internal processes to fully exploit potential advantages, most importantly in terms of costs (level three). In this regard, it should not be forgotten that competition in port communities plays an important role and heavily impacts the willingness to share operational data, which represents a key success factor of current smart port initiatives. Moreover, the integration of several data sources will enable a more precise and active assistance of port actors during port operations. Thus, it becomes apparent that the success is dependent on the willingness of actors to actively follow recommendations during operations; otherwise, the full potential of business network redesign cannot be achieved. The ABP 2020 project in the Port of Algeciras Bay reflects some main findings of our study. In the first phase of the project, they focus on adapting IT/IS infrastructure in order to improving collaboration and network synergies in the second phase. This demonstrates that an analysis and understanding of digitalization in ports is increasingly important.

Current initiatives further point out the importance of data processing and analytics. In this regard, we observe that the exploitation of new and existing data sources is increasingly regarded as a competitive advantage in the maritime industry as resulting decision support may lead to more efficient port operations. As indicated, the success of the digital transformation is again highly dependent on a related redesign of business processes and the willingness of port actors to collaborate with the port (level three and level four). This builds the basis for optimization approaches, using information of datadriven analytics, applied on the port level, referred to as meta-analytics. Finally, strategic cooperation and information flows between ports become increasingly important, in particular, to enhance cargo flows in feeder and short sea operations between connected ports.

\section{Implications and Challenges}

In the previous section the progress of digital transformation in ports and trends towards smart ports 
have been identified and analyzed. The key implications are summarized in the following.

- IT/IS as an enabler: Modern IT/IS implementations can help to address major issues in ports and build a basis for innovative just-in-time logistics or realtime control of traffic flows to strengthen competitiveness. However, achieving this is mainly dependent on the actors' and port's capability in adapting individual processes and improving process interfaces by integrating and harmonizing individual IT/IS implementations.

- Inter-organizational alignment: The previous aspect necessitates an alignment of digital strategies between involved actors. Our study emphasizes that this alignment needs to be performed on several levels to benefit from crossfertilization. Among actors in ports, however, we observe that the degree of digitalization varies markedly. While large port actors show a high degree of digitalization, smaller actors (e.g., empty container depots), having fewer financial resources and IT expertise, are often lagging behind.

- Impact of competition: Innovation at ports is driven by the strong global competition among ports as well as on a local port level. In this regard, we see that digital transformation can lead to competitive advantages, but also triggers competition on a local level. The latter may hinder the achievement of global competitive advantages, e.g., caused by concerns and an unwillingness to participate.

- Impact of central entities: Digital transformation tends to increase the influence of central control entities, like port authorities. Although a central entity is needed to manage the information exchange and to improve port operations on the overall port level, it may lead to concerns about the autonomy and individual interests of actors.

- Stakeholder involvement: To enable coordinated activities, implementation issues have to be resolved jointly. Stakeholders need to be involved in an early stage of development.

Based on the outcomes of our analysis, we next identify critical aspects and challenges to be considered.

- Comprehensive and consistent digital strategies: Rather than just adopting most innovative IT solutions, it is essential to first evaluate competitive potentials, integration with the existing port IT/IS infrastructure [5], and alignment with individual processes and the port business network. In smart ports, only the integration of different solutions enables to adequately redesign processes and networks. Especially less powerful actors need to be supported either by the port authorities or governmental bodies in order to reach the degree of digital transformation necessary to efficiently integrate processes with other actors and avoid breaks in the flow of information. It is further important to critically evaluate IT/IS investments and estimate the return on investment (ROI) of digital strategies. Due to a growing complexity and network effects, however, it is difficult to estimate value of smart port initiatives in monetary terms.

- Expertise: The adoption and ubiquitous use of IT/IS in ports require a high degree of IT/IS knowledge. Moreover, solutions need to be developed to exploit real-time information in order to improve and speed-up decision making. Thus, ports require experts like computer scientists, mathematicians, and data scientists having a solid foundation in modeling, analytics, statistics, and software engineering. To steer digital transformation into the right direction, however, these areas of expertise need to be combined with a detailed knowledge of port operations requiring at least dedicated study and training programs. As this expertise could be offered by consultancy and IT firms, ports need to rethink their role in digitally transforming the port.

- Acceptance: A systematic approach for developing and introducing smart port solutions is necessary to gain acceptance in the port community. This includes an on-going interaction with stakeholders during all phases of the project. After the development of a new smart port solution, this may also include a pilot stage for demonstrating the solutions completed by workshops and trainings. Most importantly, stakeholders need to realize the benefits for their own business. Another important success factor is trust. Technically, the way of handling cyber security is of importance. Another relevant aspect is the question whether the solution has negative effects on the competitiveness of individual actors. Systematic approaches to evaluate and secure information in coalitions are important.

- Interdisciplinary research: Collaboration between universities and ports is not only necessary to establish new educational programs, but also to extend existing knowledge. This includes, as mentioned before, the application of decision analytics, meta-analytics, and data science to develop models and methods able to exploit data sources. Moreover, innovative approaches to prepare, disseminate, and visualize data for operations and training need to be explored considering existing research efforts including augmented and virtual reality, gamification, and human-computer interaction. 


\section{Conclusion and Outlook}

The adoption of IT/IS has repeatedly paved the way for modernization in seaports. In this paper, we analyzed the levels of digital transformation that needed to take place in the past for redesigning processes, forming inter-organizational networks, and extending the variety of services necessary to achieve competitive advantages, e.g., in the form of cost, visibility, productivity, efficiency, and safety improvements. For this purpose, we reviewed main events and drivers, classified in three generations of digital transformation. By applying a well-recognized model from the literature, we analyzed the levels of digital transformation in each generation, considering the interrelationships between different stages of digital transformations and the outcomes thereof.

For the future modernization of ports, this study clearly indicates the importance of the interplay between port-centric and local IT/IS as well as process adaptations. A successful cross-fertilization can lead to competitive advantages for both the overall port and individual port actors; vice versa, ignoring trends may lead to disadvantages in form of losing important clients or being unable to participate in data-driven port operations. However, the degree of digitalization and inter-organizational integration varies a lot among port actors and may lead to breaks in information flows.

In this context, we further observe the strong dependence on network effects, in particular regarding the introduction of inter-organizational information platforms. More research is necessary to understand the value proposition, costs, power structures, and potential conflicts in those business networks considering information exchange within the port and among different ports. This study further emphasizes the incremental development stages in different generations of digital transformation. In this regard, it is important to steadily identify and evaluate new approaches helping to shape strategies and activities of ports and port actors. While the focus of current smart port initiatives is on IT/IS adoption and integration, we see a growing need for models and methods able to fully exploit new IT/IS capabilities and related sources of (real-time) data. These approaches might extend known decision support approaches (see, e.g., [8]). This is an area where multidisciplinary research is urgently required. While recent research focuses predominantly on dedicated areas in ports, especially on container terminals, it becomes further important to investigate interfaces between individual processes and propose integrative approaches improving the coordination and management of activities being performed in different areas by different actors, and under varying conditions, including transport demand fluctuations, traffic and weather conditions, and cascading errors. An example for recent research activities can be found in the area of inter-terminal transportation, predominantly focusing on optimization and simulation approaches. Therefore, we endorse approaches on (real-time) data-driven decision support (e.g., meta-analytics) and innovative ways to incorporate them into port operations and training (e.g., augmented and virtual reality, gamification, etc.).

\section{References}

[1] N. Venkatraman, "IT-enabled business transformation: From automation to business scope redefinition", Sloan Management Review, vol. 35, no. 2, pp. 73-87, 1994.

[2] L. Heilig and S. Voß, "Information systems in seaports: A classification and overview", Information Technology and Management, submitted.

[3] T. H. Davenport, "Process Innovation: Reengineering work through information technology", Harvard Business School Press, 1993.

[4] S. Guha, V. Grover, W. J. Kettinger and J. T. Teng, "Business process change and organizational performance: Exploring an antecedent model", Journal of Management Information Systems, vol. 14, no. 1, pp. 119-154, 1997.

[5] N. Venkatraman, J. C. Henderson and S. Oldach, "Continuous strategic alignment: Exploiting information technology capabilities for competitive success", European Management Journal, vol. 11, no. 2, pp. 139-149, 1993.

[6] A. Bharadwaj, O. A. El Sawy, P. A. Pavlou and N. Venkatraman. "Digital business strategy: Toward a next generation of insights", MIS Quarterly, vol. 37, no. 2, pp. 471482, 2013.

[7] W. Talley (ed.) "The Blackwell Companion to Maritime Economics", Wiley-Blackwell, Chichester, 2012.

[8] R. Stahlbock and S. Voß, "Operations research at container terminals: a literature update", OR Spectrum, vol. 30, no. 1, pp. $1-52,2008$.

[9] United Nations, "Value-added services of logistics centres in port areas", Commercial Development of Regional Ports as Logistics Centres, pp. 19-34, 2002.

[10] J. E. Lee-Partridge, T. S. H. Teo and V. K. G. Lim, "Information technology management: The case of the Port of Singapore Authority", Journal of Strategic Information Systems, vol. 9, no. 1, pp. 85-99, 2000.

[11] B. W. Wiegmans, A. Van der Hoest and T. E. Notteboom, "Port and terminal selection by deep-sea container operators", Maritime Policy \& Management, vol. 35, pp. 517-534, 2008.

[12] PEMA, "Laser technologies in ports and terminals", Tech. rep., 2015.

[13] A. A. Palis and P. W. De Langen, "Seaports and the structural implications of the economic crisis", Research in Transportation Economics, vol. 27, no. 1, pp. 10-18, 2010.

[14] PEMA, "Container terminal yard automation", Tech. rep., 2012.

[15] L. Heilig, E. Lalla-Ruiz and S. Voß, "port-IO: A mobile cloud platform supporting context-aware inter-terminal truck routing", European Conference on Information Systems (ECIS), Istanbul, Turkey, pp. 1-10, 2016. 